\title{
El ecoturismo comunitario como alternativa económica en las comunidades de Musawas, Wilu y Panyawas, del Territorio Mayangna Sauni As
}

\section{Maritza del Carmen Taylor Frank}

\section{INTRODUCCIÓN}

La iniciativa de esta investigación surge para poder contar con un estudio base de ecoturismo comunitario que dé a conocer la riqueza de recursos naturales y paisajísticos de tres comunidades del territorio indígena Mayangna Sauni As, y que permita a la vez la conservación de estos recursos cuyos guardianes ancestrales han sido los pobladores sumu-mayangnas que habitan este Territorio. También esta investigación se ha ejecutado con el fin de que las autoridades territoriales y los líderes comunales cuenten con insumos que les permitan materializar una idea de desarrollo ecoturístico, ya que en el estudio se señalan sitios específicos en tres comunidades (Musawas, Wilu y Panyawas) del territorio Mayangna Sauni As, donde pueden llevarse a cabo estas actividades ecoturísticas.

En el curso de esta investigación se ha consultado fuentes escritas. Sin embargo, las fuentes más importantes han sido los propios comunitarios objetos de esta investigación. Al final se encuentra un listado de todos estos informantes por comunidad.

\section{Ecoturismo comunitario}

El ecoturismo comunitario es una actividad cuya planificación y gestión económica, social y física se realiza con y para las comunidades locales, contribuyendo a la conservación de los recursos naturales y a la integridad de la cultura de las mismas, promoviendo en los residentes sensibilización política, económica y ambiental de los beneficios y ventajas de la preservación y sostenibilidad de los recursos turísticos. (Ramírez, Margarita 2011).

En el turismo ecológico o ecoturismo se privilegia la sustentabilidad, la preservación y la apreciación del medio (tanto natural como cultural) que acoge a los viajantes. Aunque existen diferentes interpretaciones, por lo general el turismo ecológico se promueve como un turismo "ético", en el cual también se presume como primordial el bienestar de las poblaciones locales, y tal presunción se refleja en la estructura y funcionamiento de las empresas/grupos/ cooperativas que se dedican a ofrecer tal servicio. En ese sentido en este estudio se asume el concepto de ecoturismo ya que sus componentes esenciales de preservación de la naturaleza y los ecosistemas se basan en la participación local, y los resultados económicos de dicha actividad quedan para beneficio de las propias comunidades.

Se definen como puntos de interés eco turístico todos aquellos lugares con escenarios naturales y ecosistemas que permitan el avistamiento de flora y fauna, el conocimiento y aprendizaje del cuido de los recursos naturales. Se enfatiza que el concepto a manejarse en el territorio Mayangna Sauni As es el de ecoturismo, pues conllevan implicito el concepto de conservación. Cabe señalar que en este momento no existe en el territorio ningún tipo de actividad ecoturística organizada por las comunidades indigenas y para el beneficio comunitario.

Esta Investigación se ha realizado en cinco meses de continuo trabajo con los comunitarios y líderes y también a través de entrevistas y visitas de reconocimiento a los potenciales puntos turísticos en el Territorio. Esto nos ha permitido identificar y describir los atributos turísticos de los puntos geográficos donde se puede desarrollar el ecoturismo comunitario, y conocer al mismo tiempo la percepción general de los comunitarios y líderes sobre esta propuesta turística.

Es importante mencionar que esta forma de turismo comunitario permite desarrollar y fomentar valores 
históricos y culturales dentro de las comunidades, ya que el turismo comunitario no es exclusivo para los recursos de flora y fauna, sino que también comprende recursos culturales que nuestros ancestros practicaban, como ritos, leyendas, mitos y hechos trascendentales que marcaron la historia de las comunidades involucradas.

\section{Antecedentes de algunos estudios sobre la riqueza de flora y fauna en Bosawas}

Para nuestro estudio es de suma importancia mencionar algunos aportes o antecedentes que enriquecen nuestra temática de investigación y sustentan la viabilidad del turismo ecológico en reservas como Bosawas, el sitio en que se encuentran nuestras comunidades de estudio. En relación al ecoturismo comunitario se logró identificar el estudio de $\mathrm{TNC}^{\mathrm{l}}$ (1994), que nos brinda algunos aportes sobre el ecoturismo. Aunque en dicho texto no se aborda con suficiente dedicación el tema ecoturístico en los territorios sumu-mayangnas, sin embargo, a través de mapas y textos alusivos logra enriquecer nuestra investigación.

En el cuadro siguiente se ubican los lugares con mayor potencial ecoturístico y cultural de la zona, a partir de la información proporcionada a TNC por los propios habitantes indígenas de las comunidades involucradas en esta investigación:

\begin{tabular}{|c|c|c|c|}
\hline Leyenda & Valor & Significado & 8. Tugar \\
\hline Kal Lalamna & Cultural e histórico & $\begin{array}{l}\text { Ritos del dios Asangha, } \\
\text { para responder a los ataques } \\
\text { miskitos. Desaparecer } \\
\text { del mundo visible por } \\
\text { determinado tiempo. }\end{array}$ & $\begin{array}{l}\text { Asang Subagni (caño del cerro } \\
\text { agudo), cerros Yaluka y Aluka. }\end{array}$ \\
\hline Asang Lawana & Cultural e histórico & $\begin{array}{l}\text { Graduación de los caciques } \\
\text { mágicos }\end{array}$ & $\begin{array}{l}\text { Dulaibin Asangni, Kuhkana } \\
\text { Was }\end{array}$ \\
\hline Asang Lawana & Cultural e histórico & $\begin{array}{l}\text { Prueba de madurez para el } \\
\text { matrimonio }\end{array}$ & Dulaibin Asangni \\
\hline Yalkalpurna & Social tradicional & Resolver la viudez de mujeres & $\begin{array}{l}\text { Wiyunak Was Sahni, Panya } \\
\text { Asangni, Mura Was Langni, } \\
\text { Suba Kitang, Suba SakAsang }\end{array}$ \\
\hline Alkalpurna & Social y tradicional & Resolver la viudez de varones & $\begin{array}{l}\text { Wiyunak Was Sahni, Panya } \\
\text { Asangni, Mura Was Langni, } \\
\text { Suba Kitang, Suba Sak Asang }\end{array}$ \\
\hline Sitios de aprendizaje & Social y tradicional & Sitios de aprendizaje & $\begin{array}{l}\text { Antiguas comunidades Ki } \\
\text { Sahna (Peña Partida), Urus } \\
\text { Takna, Wayan Was,Suni Was, } \\
\text { Silamkipala, Daka Daihni y } \\
\text { Ulmak Was. }\end{array}$ \\
\hline Dikutna & Cultural e histórico & $\begin{array}{l}\text { Sitio donde estalló, según la } \\
\text { leyenda, una bomba atómica } \\
\text { miskita (dikutna) y donde } \\
\text { sobrevivió el cacique mágico } \\
\text { SulBa }\end{array}$ & $\begin{array}{l}\text { Cerro nublado, el cerro más } \\
\text { alto del territorio Mayangna } \\
\text { Sauni As, ubicado entre las } \\
\text { cuencas Kwuabul y Kahka } \\
\text { Was }\end{array}$ \\
\hline
\end{tabular}

Fuente: TNC: 1994

1 The Nature Conservancy 
Mapa de puntos de interés ecoturístico y cultural en el territorio MSA en Bosawas

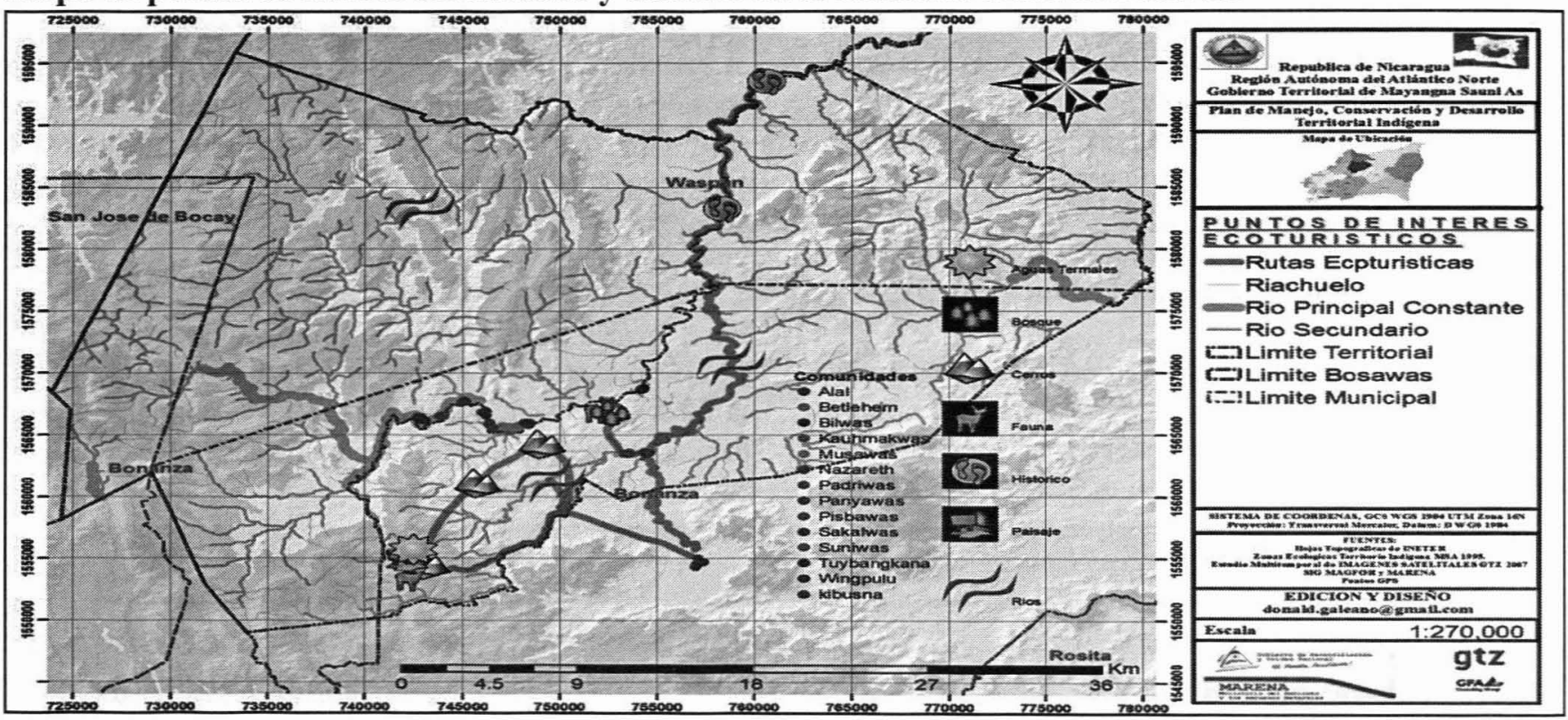

Fuente: Mapeo Comunitarios en Taller con Autoridades Territoriales MSA (Mapa Topográfico 1:50,000 I)

Existe otra investigación sobre la rica biodiversidad de la vegetación y los patrones de abundancia de mamíferos y aves, en la reserva Bosawas. Este estudio contó con el concurso de las comunidades indígenas. Fue una investigación que duró seis años y fue ejecutada por un equipo coordinado por la doctora Kimberly Williams (2006) y promovido por la universidad de Michigan y el zoológico de San Luis, Missouri. Esto es importante para nuestros fines de desarrollo turístico, puesto que una de las variables de importancia del ecoturismo comunitario es la flora y la fauna.

\section{CARACTERIZACIÓN DE LAS COMUNIDADES DE MUSAWAS, WILU Y PANYAWAS, EN EL TERRITORIO MAYANGNA SAUNI AS (MSA)}

El pueblo sumu-mayangna está radicado principalmente en nueve territorios de diferentes municipios en las dos Regiones Autónomas y en el departamento de Jinotega. Uno de ellos, el más extenso $\left(1,638.10 \mathrm{~km}^{2}\right)$ y más poblado es el territorio Mayangna Sauni As. Este Territorio fue el primero en lograr su titulo territorial, en el año 2007. Está clasificado en seis categorías de uso (MARENA \& GTI, 2007) y dividido en tres sectores importantes: el Sector 3 corresponde a la cuenca del majestuoso río Waspuk, que asienta en sus riberas ocho comunidades sumu-mayangnas entre las cuales están localizadas las tres que son objetos de nuestro estudio:

Musawas está considerada la capital del pueblo sumumayangna. Se encuentra ubicada en la parte superior del río Waspuk. Frente a ella se observa el imponente cerro Isahmul. Su población es de aproximadamente 5,000 habitantes. Las casas están construidas de madera, y de zinc los techos, aunque algunas casas tienen techo de palma natural.

Panyawas está localizada en la parte superior del río Waspuk, a un $\mathrm{km}$ de la comunidad de Musawas a donde se puede llegar a caballo o en pipante. Está rodeada de árboles frondosos.

Willu está ubicada en la parte media del rio Waspuk y el Ully. A pie se llega en seis horas desde la comunidad de Musawas.

Existen algunos sitios que nuestros ancestros ocuparon para realizar ritos y asanglawana. En la actualidad, a pesar de la importancia del ecoturismo, no ha habido de parte de las autoridades comunales y territoriales una estrategia para poder potencializar las fortalezas de estas tradiciones culturales en la zona y que los comunitarios vean estas expresiones como una oportunidad de desarrollo. 


\section{Diversidad de bosques del territorio MSA}

El territorio MSA incluye dos Zonas de Vida (Sensu, Holdridge, 1947). El bosque húmedo tropical, que abarca el $85 \%$ del área, y el bosque muy húmedo premontano, que se limita a los sectores montañosos en el borde occidental y el macizo de los cerros Bakus, Asang, Kuma. Pitah y Asang, que divide el curso medio del río Waspuk en la parte central del territorio.

El bosque húmedo tropical es propio de las tierras bajas, su altitud no supera los $450 \mathrm{msnm}$ y la temperatura es mayor de $24^{\circ} \mathrm{C}$. Las especies de plantas arbóreas son el tamarindo (Dialium Guinensis), yayo, tempisque, ojoche, pasica, ojoche colorado y bambú.

El bosque muy húmedo premontano corresponde a las tierras con altitudes superiores a los $450 \mathrm{msnm}$ y temperaturas entre los $18^{\circ} \mathrm{C}$ y $24^{\circ} \mathrm{C}$. Existe una lista de 35 especies de plantas arbóreas de las cuales las más frecuentes son el tamarindo, pasica, plátano amarillo, pan blanco, y el aguacate montero

\section{Diversidad de la fauna del territorio MSA}

No se disponen de estudios actualizados sobre la fauna silvestre en el territorio; en el Plan de Manejo Territorial de Mayangna Sauni As, elaborado en 1997 con el apoyo de TNC, se identificaron 205 especies de aves, pocas de mamíferos y una sola especie de pez.

El mismo plan hace referencia a la importancia del territorio MSA como lugar de paso y refugio de aves migratorias y como sitio de residencia de especies que se encuentran amenazadas o en peligro de extinción.

En consulta con las comunidades y sobre la base de la lista de especies que requieren de veda para su protección, en el 2009 se identificó la existencia de muchas especies en peligro de extinción y que pueden convertirse en sitios de desarrollo ecoturístico, tomando en cuenta que se encuentran en veda indefinida y son especies de mucha importancia a nivel nacional.

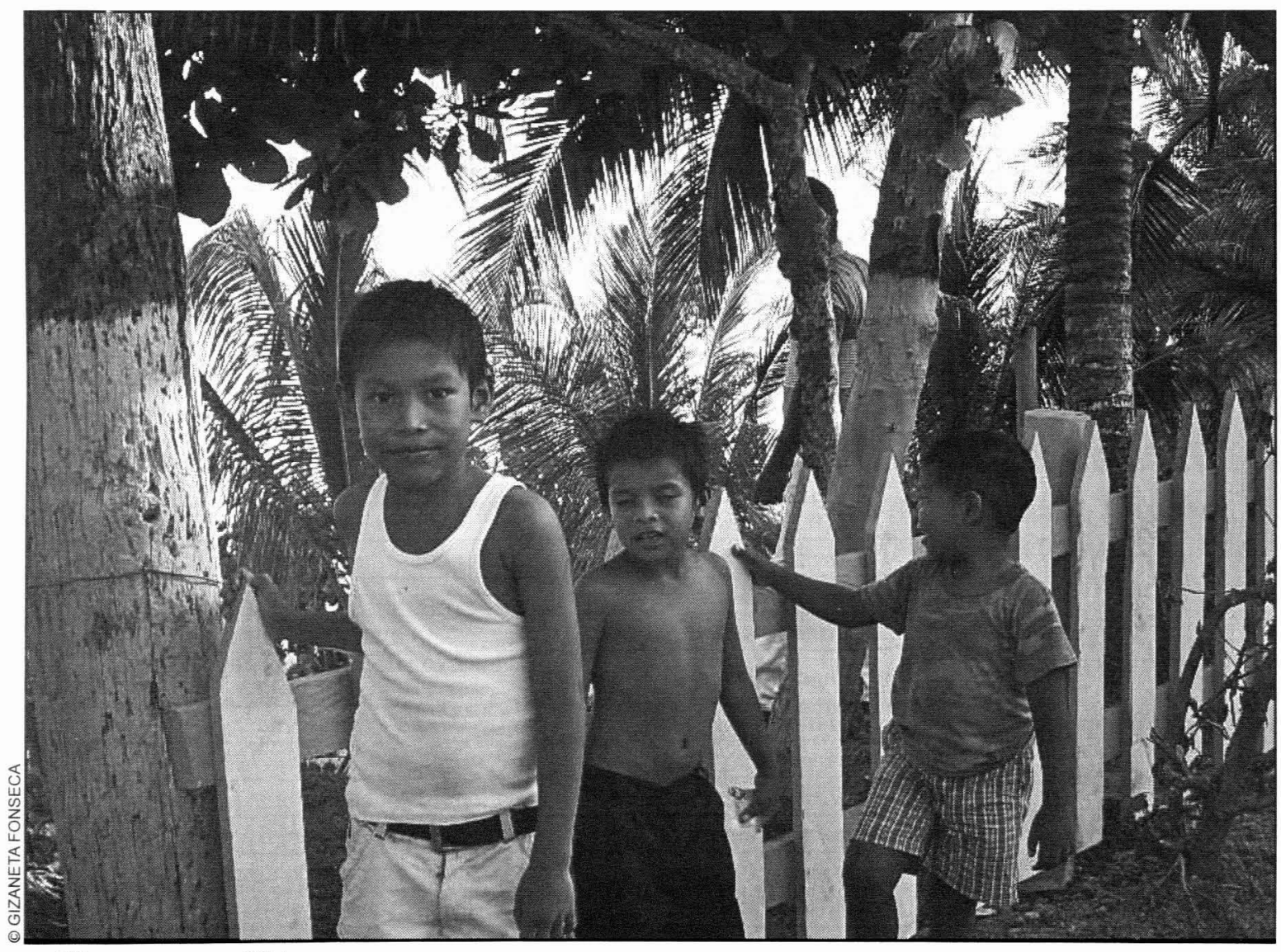

Niños mayangnas. 2011. 
Fauna con veda nacional indefinida:

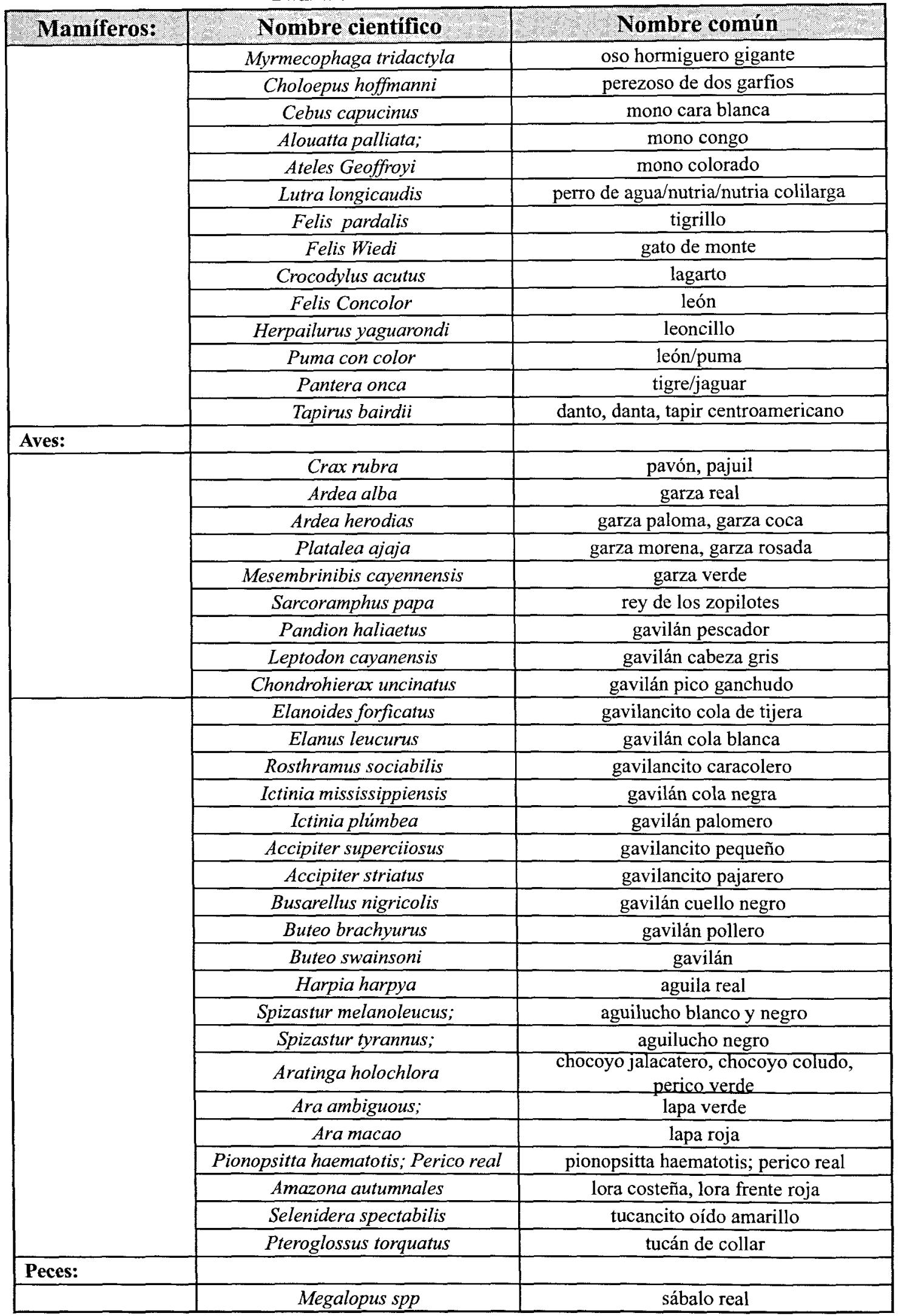




\section{Fauna con veda nacional parcial}

\begin{tabular}{|c|c|c|}
\hline Mamíferos: & Nombre cientifico & Nombre común \\
\hline \multirow{9}{*}{ Aves: } & Agouti paca & Guardatinaja, Güía \\
\hline & Dasyprocta punctata & Guatuza \\
\hline & Dasypus novemcinctus & Cusuco, Armado o Pitero \\
\hline & Nasua narica & Pizote, Pizote solo \\
\hline & Odocoileus virginianus & Venado ramazón, venado malacate \\
\hline & Tayassu pecan & Jabalí, Chancho de monte \\
\hline & Tinamus major; & Gallinita de monte \\
\hline & Ortalis vetula; & Chachalaca vientre claro \\
\hline & Aramides cajanea & Gallina poponé \\
\hline \multicolumn{3}{|l|}{ Reptiles: } \\
\hline & Ctenosaura similis; & Garrobo negro \\
\hline & Iguana iguana; & Garrobo lapa \\
\hline & Boa constrictor; & Boa común \\
\hline & Lmpropeltis triangulum; & Falso coral \\
\hline & Rhinoclemmys annulatta; & Tortuga de tierra \\
\hline \multicolumn{3}{|l|}{ Reptiles Anfibios: } \\
\hline & Agalychnis callidryas; & Rana ojos rojos \\
\hline & Dendrobates auratus; & Ranita dorada \\
\hline & Dendrobates pumilio; & Ranita de sangre \\
\hline \multicolumn{3}{|l|}{ Peces: } \\
\hline & Centropomus parallelus; & Róbalo \\
\hline \multicolumn{3}{|l|}{ Moluscos: } \\
\hline & Strombus gigas; & Caracol del Caribe \\
\hline \multicolumn{3}{|l|}{ Moluscos Crustáceos: } \\
\hline & Macrobranchium carcinus; & Camarón de río \\
\hline
\end{tabular}

Algunas de estas especies forman parte de la dieta alimentaria indígena. Para su aprovechamiento se cumplen normas de cuota de caza en la zona de uso correspondiente. Los comunitarios mencionan como mayor consumo en su alimentación: wiya (165 animales cazados), venado (72), guatusa (59) y armadillo (38).

El 95\% de los animales reflejados en el cuadro son consumidos en las tres comunidades, con excepción del jaguar. También especies acuáticas (hídricas) son muy abundantes $(90 \%)$

\section{Hidrología e hidrografía del territorio MSA}

Los ríos que existen en el territorio Mayangna Sauni As pertenecen a la cuenca Somoto-Jinotega, cuyo drenaje principal es el río Coco. Solo el sector oriental del Territorio pertenece a la cuenca Wawa. Esto es de importancia para el aprovechamiento ecoturístico de las cuales podemos observar en el siguiente cuadro:

\section{Cuencas y sub-cuentas del territorio MSA}

\begin{tabular}{|l|l|}
\hline \multicolumn{1}{|c|}{ Cuencas } & \multicolumn{1}{|c|}{ Sub-cuenca } \\
\hline $\begin{array}{l}\text { Cuenca Somoto- } \\
\text { Jinotega } \\
\text { Sub cuenca Was } \\
\text { Saa (Waspuk) }\end{array}$ & $\begin{array}{l}\text { Pispis, Kwahbul, Bilwas, } \\
\text { Matanak Was, Sulun Was, } \\
\text { Wahka Was, Uly was, Daka }\end{array}$ \\
\hline $\begin{array}{l}\text { Sub Cuenca Walak } \\
\text { Was }\end{array}$ & Makiupit Was, Ki Rah Was. \\
\hline $\begin{array}{l}\text { Cuenca Wawa, } \\
\text { Wawa Was. }\end{array}$ & $\begin{array}{l}\text { Walak Was, Kuring was, } \\
\text { Wabauni Was, Wawasa Was, } \\
\text { Was, Kauhmak Was Wasni. }\end{array}$ \\
\hline
\end{tabular}

Fuente: Mapa de Cuencas y Sub-cuencas, INETER 


\section{Mapa de Recursos Hídricos del territorio MSA}

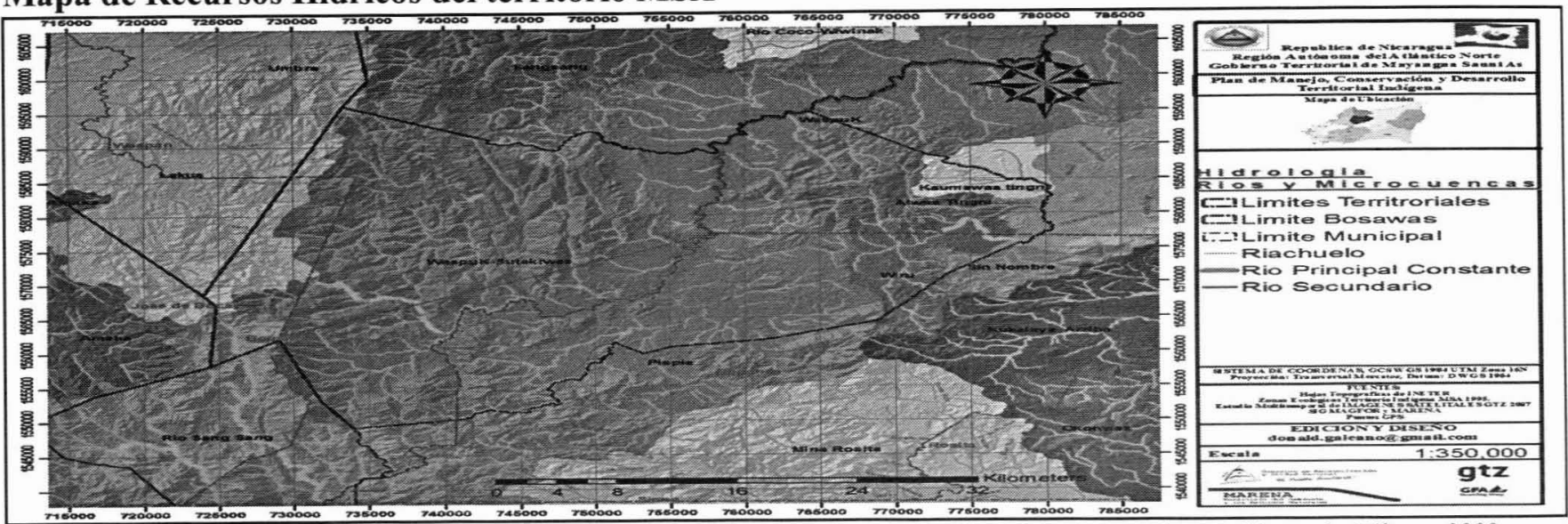

Fuente: Análisis multitemporal del Cambio de Uso del Suelo en base a imágenes satelitales del área afectada por el huracán Félix en 2000

Los acuíferos tienen una reserva permanente de agua y una reserva reguladora que son continuamente abastecidos por la infiltración del agua de lluvia y otras fuentes subterráneas. Las reservas reguladoras dan origen a los manantiales, arroyos, ríos, etcétera, es decir, a las zonas de descarga por donde las aguas emergen del acuífero.

En el Territorio de MSA, se han identificado zonas con potencial de recarga ubicadas en los cerros más altos.

\section{RESULTADOS}

\section{Sitios para el desarrollo del ecoturismo comunitario en Musawas, Wilu y Panyawas, del territorio MSA}

Los sitios inventariados para llevar a cabo el ecoturismo en todas las dimensiones que hemos contemplado son los siguientes:

\section{Comunidad de Musawas}

\section{Sitio Eco Turístico: Cerro Isahmul}

\begin{tabular}{|c|c|}
\hline Tipo de recurso & Florística y faunística. \\
\hline Ubicación & $\begin{array}{l}\text { Se encuentra ubicado frente a la comunidad de Musawas } \\
\text { a quince minutos de camino. }\end{array}$ \\
\hline Acceso al lugar & Se puede acceder a través de bestias o a través de vehículos. \\
\hline Qué se ofrece & Actualmente no se ofrece ningún tipo de servicio ecoturístico. \\
\hline Oferta turística & $\begin{array}{l}\text { - La creación de un pequeño hotel turístico con sede en Musawas, donde se puedan } \\
\text { desarrollar actividades culturales antes de los recorridos: } \\
\text { - Actividades artísticas (bailes, danzas, etcétera). } \\
\text { - La principal gastronomía de los sumu-mayangnas (dîkuruhna, wasakuruhna, ulang } \\
\text { satni disubang, busna, entre otros). } \\
\text { - Se puede realizar recorridos en las montañas donde abundan árboles como: roble y santa } \\
\text { maría. } \\
\text { - También existe una cantidad de animales como: guardiola, guatusa, cusuco y otros } \\
\text { animales salvajes que con un manejo responsables puede servir como recorrido turístico } \\
\text { por parte de los visitantes. } \\
\text { - Se puede desarrollar la actividad artesanal (tuno). }\end{array}$ \\
\hline $\begin{array}{l}\text { Acciones para } \\
\text { desarrollar el } \\
\text { ecoturismo }\end{array}$ & $\begin{array}{l}\text { - Elevar propuestas a los líderes territoriales para buscar financiamiento. } \\
\text { - } \quad \text { Gestionar con organismo gubernamentales. }\end{array}$ \\
\hline
\end{tabular}




\section{Comunidad de Panyawas}

Frente a la comunidad de Panyawas hay un cerro llamado Baba Asang donde se encuentra abundante flora y fauna, pero también se caracteriza por tener ríos. Allí es posible desarrollar actividades turísticas. Se puede ver los fósiles de una boa gigantesca que permanecen en el sitio desde hace mucho tiempo. Desde la entrada a la comunidad, hasta el cerro se encuentra abundancia de recursos naturales, incluyendo flora y fauna, así como recursos hídricos.

\begin{tabular}{|c|c|}
\hline Tipo de recurso & Hidrográfico, faunístico y florístico. \\
\hline Ubicación & Se encuentra ubicado a $2 \mathrm{~km}$ de la comunidad. \\
\hline Acceso al lugar & Se puede llegar caminando y a través de bestias. \\
\hline Oferta turística & Únicamente se ofrece el recorrido por el sitio. \\
\hline Qué se podría ofrecer & $\begin{array}{l}\text { - } \quad \text { Desarrollo de un pequeño hotel turístico. } \\
\text { - Se podrían desarrollar recorridos en el cerro por diferentes puntos donde } \\
\text { se encuentran importantes paisajes. } \\
\text { - También se encuentran recursos faunísticos como: carne de wiya, chancho } \\
\text { de monte, entre otros. } \\
\text { - Se encuentran importantes puntos sobre el rio Waspuk que pueden servir } \\
\text { como balnearios. } \\
\text { - El desarrollo de un parque arqueológico y paleontológico; se han encontrado } \\
\text { piezas arqueológicas, así como restos de una serpiente gigantesca, que } \\
\text { podrían incluirse }\end{array}$ \\
\hline Acciones para desarrollar & $\begin{array}{l}\text { - Elevar propuestas a los gobiernos territoriales y no gubernamentales. } \\
\text { - } \quad \text { Capacitar a los comunitarios y líderes para llevar a cabo el ecoturismo. }\end{array}$ \\
\hline
\end{tabular}

\section{Comunidad Willu}

En la comunidad de Willu, los entrevistados expresaron que a una distancia de seis horas hay un salto llamado Ulukumak donde se puede visitar un lugar turístico para llevar un mutuo entendimiento del ambiente. Para llegar hasta el lugar indicado el recorrido dura tres días desde el municipio de Bonanza. Primeramente se sale con transporte terrestre hasta la comunidad de Suniwas, y luego con bestia; después, con pipante hacia la comunidad de Willu, y al siguiente día se sale con destino al salto Ulukumak (el punto indicado).

\begin{tabular}{|l|l|}
\hline \multicolumn{2}{|c|}{ Sitio ecoturístico Salto Ulukumak } \\
\hline Tipo de recurso: & hidrográfico (salto) \\
\hline Ubicación & $\begin{array}{l}\text { Se encuentra ubicado a seis horas de la comunidad de Willu, en la parte alta del } \\
\text { rio Waspuk. }\end{array}$ \\
\hline Acceso al lugar & $\begin{array}{l}\text { La movilización primeramente es en un medio transporte terrestre y posteriormente } \\
\text { vía acuática en pipante }\end{array}$ \\
\hline Qué se ofrece & Actualmente solamente se ofrece recorridos en el lugar. \\
\hline
\end{tabular}




\begin{tabular}{|l|l|}
\hline \multirow{4}{*}{ Qué se podría ofrecer } & - Desarrollar a lo inmediato una infraestructura básica para los turistas. \\
& - El desarrollo de la artesanía (tuno). \\
& - Recorridos por los senderos y ríos. \\
& - Vista de animales. \\
\hline \multirow{2}{*}{ Acciones para desarrollar } & - Elevajes naturales. \\
\hline
\end{tabular}

\section{Percepción sobre el ecoturismo comunitario en Musawas, Willu y Panyawas}

Para este estudio era de suma importancia conocer la percepción que tienen los comunitarios y líderes de las comunidades, acerca del tema de ecoturismo,

En la comunidad de Musawas, los comunitarios consultados afirmaron, en un $80 \%$, de los pobladores no tienen ningún conocimiento acerca de lo que es ecoturismo; igualmente, esta cifra se reflejó en las comunidades de Wilu y Panyawas. Sin embargo, una vez que se explicó el concepto lograron entender de manera general el ecoturismo como cualquier actividad en que se observa toda la naturaleza y los recursos naturales y espirituales que se observan dentro de nuestro territorio, tales como los animales, las plantas, los ríos, la historia, los cuentos, etcétera. Algunos líderes comunitarios expresaron, sin embargo, que han escuchando, de parte de profesionales que han hecho algunos estudios en las comunidades, que el ecoturismo se da en sitios donde abundan o se conservan diferentes recursos naturales que tiene su zona o comunidad.

Un $70 \%$ de los líderes comunales que desconocían el tema, luego de una explicación expresaron que sería una oportunidad para desarrollar de manera sostenible los recursos que ofrecen los territorios sumu-mayangnas. Esto se reflejó en las tres comunidades de estudio.

Los miembros del gobierno territorial por su parte expresaron que se ha llevado a cabo un proyecto de ecoturismo en la comunidad de Suniwas de Palang, a través de la construcción de un un local para desarrollar esta actividad, sin embargo fracasó por falta de financiamiento.

Una vez explicada la importancia de lo que es el ecoturismo, los ancianos, mujeres y estudiantes expresaron su conocimiento acerca de la abundancia de variedades de árboles y buenos arbustos con flores, que se observa en la naturaleza: Desde hace mucho tiempo, nuestros abuelos los han venido conservando y preservando, con la finalidad de que estos recursos sean para aprovechamiento y contribuyan a la sobrevivencia de toda la nación sumumayangna. También expresaron que, en cuanto a la fauna, existe una gran cantidad de animales tanto silvestres, como domésticos y acuáticos. Todos estos recursos los ocupamos como alimento y una poca cantidad se comercializa (danto, mono, jabalí) dijeron los ancianos, mujeres y estudiantes.

Las características geográficas que presentan las tres comunidades estudiadas del territorio Mayangna Sauni As, muestran que la mayoría de los habitantes viven en la orilla de los ríos y en algunos casos tienen saltos de agua, esto permite observar que ellos entienden con mayor facilidad la importancia de lo que es el ecoturismo.

Dentro del territorio Mayangna Sauni As existen grandes ríos caudalosos, como el Waspuk, el Pis Pis, el salto de agua conocido como el Ulukumak, que se encuentra ubicado en la comunidad de Willu. De tal manera que los recursos hídricos, faunístico y florísticos pueden combinarse con los recursos culturales, que puedan permitir un aprovechamiento sostenible y una oportunidad de desarrollo para las comunidades sumumayangnas, como los sitios sagrados ceremoniales y algunos rituales en la comunidad de Willu; igualmente, la tumba del cacique Archibol, que se conserva todavía, y el centro Ulukumak.

El comunitario de Musawas Simón Davis Rufus nos comentaba que existen sitios de importancia para el desarrollo del ecoturismo, como: Asang Rarah, Yaluk (Yal Asang), Aluk (Al Asang), cerro Isahmul. El ecoturismo es una actividad con enfoque de desarrollo sostenible, que puede servir para reducir los altos índices de pobreza y lograr un bienestar en las comunidades; ya que actualmente la mayoría de las familias son de escasos recursos económicos y se dedican a la agricultura, ganadería, pesca, comercio, güirisería y un porcentaje reducido son trabajadores del Estado. 
Es importante resaltar que los lideres comunales como los wihta y los sindicos expresaron que es necesario tener un punto de ecoturismo donde los otros grupos étnicos visiten nuestro territorio para tener una buena relación, debido a que es una región con una riqueza pluricultural y se puede entablar una relación con las otras etnias.

Analizando los puntos de vista de los líderes sumumayangnas del territorio Sauni As, nos hace reflexionar acerca de algunas debilidades de los gobiernos territoriales, como los aspectos organizativos y la ejecución de proyectos realistas y con carácter progresivos en los territorios. Se menciona el lugar ecoturístico llamado Palang, que se encuentra ubicado a una hora de la comunidad de Suniwas, que representó una de las propuestas iniciales de ecoturismo por su abundantes recursos naturales, sin embargo se detuvo por falta de recursos.

Algunos visitantes o personas ajenas a la comunidad son atraidos por las diferentes plantas que se observa alrededor de las comunidades, por tanto el desarrollo del ecoturismo dentro de las tres comunidades (Musawas, Panyawas y Willu) no traería destrucción al medio ambiente.

\section{CONCLUSIONES}

Por las caracteristicas generales que presentan las tres comunidades donde se desarrolló la investigación se llegó a la conclusión de que los comunitarios conocen elementos de ecoturismo comunitario, entendido éste como el conjunto de recursos naturales que posee la comunidad y que pueden ser aprovechados para reducir la pobreza.

Según las caracteristicas de las comunidades estudiadas del territorio Mayangna Sauni As, éstas poseen gran variedad faunistica y floristica; rios caudalosos, saltos y cerros espectaculares; sitios históricos y un pueblo indigena sumumayangna rico en tradición y manifestaciones culturales que se denotan en su artesanía, cuentos, leyendas y mitos interesantes. Todos estos son elementos necesarios para un potencial desarrollo del turismo comunitario y también el turismo científico.

Entre los escenarios paisajísticos se destacan en Musawas el cerro Isahmul; en Panyawas, el Baba Asang, y en Willu el Ulukumak.

Dentro del territorio Mayangna Sauni As, el $85 \%$ de los recursos naturales están conservados y listos para despegar un proyecto de turismo ecológico comunitario. Sin embargo, esto no se lleva a cabo por la falta de iniciativa y organización de los comunitarios y de los lideres comunales y territoriales. También, por falta de voluntad política de autoridades municipales, regionales y nacionales.

\section{RECOMENDACIONES}

A través del presente trabajo investigativo sobre el desarrollo de ecoturismo comunitario en tres comunidades del territorio Mayangna Sauni as se recomienda lo siguiente:

A. A los comunitarios:

- Cuidar de los recursos naturales que dispone el territorio (flora, fauna y patrimonio cultural).

- Respetar las leyes generales que protegen el medio ambiente.

- Organizarse con el objetivo de realizar propuestas a los líderes territoriales para el -desarrollo ecoturístico en las comunidades.

- Realizar intercambio de experiencia con los actores que ya tienen conocimientos en ecoturismo

\section{B. A los líderes comunales:}

- Reunirse constantemente para llevar una buena comunicación con los comunitarios y abordar en esos encuentros el tema del ecoturismo.

- Exponer al Gobierno Territorial las oportunidades que ofrece el ecoturismo comunitario para buscar el apoyo en otras instancias.

- Monitorear las acciones de desarrollo y estrategia de gestión del Gobiemo Territorial

\section{A los líderes territoriales:}

- Proponer a las instancias superiores un proyecto sobre ecoturismo comunitario dentro del Territorio Mayangna Sauni as.

- Fortalecer toda la estructura conformada dentro de la junta directiva del Gobiemo Territorial Mayangna Sauni As, para que puedan solucionar conjuntamente algunas brechas que hay en el Territorio.

- Invertir los recursos económicos en los proyectos ecoturísticos contemplados.

- Mantener informados a los comunitarios y a los síndicos sobre todas las actividades que realizan. 
D. A las autoridades municipales, regionales y nacionales:

- Formular y gestionar proyectos que conlleven a desarrollar el ecoturismo comunitario en el territorio Mayangna Sauni As.

- Buscar y brindar espacios equitativos para el beneficio y desarrollo de las diferentes comunidades sumu-mayangnas ubicadas en el territorio Mayangna Sauni As.

\section{PERSONAS CONSULTADAS}

A continuación presentamos una lista de las personas que nos brindaron información sobre el tema:

- Musawas (15 personas): Mancio Rufus (Juez Comunal), Pichardo Fernández (Sindico), Dinatre Devis (Director de Secundaria), William Sebastian (Director de primaria), Benicio Zeledon (Gobierno territorial), Orben Zeledón (Técnico de modelo de salud), Simón Davis (Docente), Serapio Palacio (Docente), Hipólito Taylor (Docente), Mayra Fritz (Lideresa), Elba Devis (Docente), Erudita Devis
(Artesana), María Isabel Blandón (Estudiante), Rayna Smith (Docente), Aquilina Patrón (Lideresa).

- Panyawas (15 personas): Inus Díaz (Anciano), Merlo Huete (Docente), Alex Pedro (Docente), Abetnico Rufus (Comunitario), Raydel Robins (Comunitario), Roberto Taylor (comunitario), Derle Jacobo (comunitario), Derle Jacobo (Estudiante), Martiliano Simeon (Guarda bosque), Ellolita Diaz (Comunitaria), Petrona Diaz (Lideresa), Laura Jacobo (GTI), Arminda Rufus (Comunitaria), Zoila Taylor (Estudiante), Aurencia Rufus (Comunitaria).

- Willu (15 personas): José Denale palacios (Sindico), Minto Atanacio Fritz (Docente), José Samuel palacio (Anciano), Zaqueo Palacio Simeón (Comunitario), Pablo meza (Anciano) Eliticia Samuel (Comunitaria), Brenda Samuel (Comunitaria), Erasmo Robins (Comunitario) Acnicia Samuel (Facilitadora EBA), Florentina Paiza (comunitario), Precino Samuel (comunitario), Donal castillo (comunitario), Prenita Samuel (Partera) Leonel Robins (comunitario) Bertencia Samuel (Docente).

\section{Referencias Bibliográficas}

Decreto No. 3584: reglamento a la Ley No. 28, Estatuto de la autonomía de las regiones de la Costa Atlántica de Nicaragua. (1987, 30 de octubre). La Gaceta, pp. 2833-2838.

Ley No. 217. Ley general del medio ambiente y los recursos naturales. (1996). La Gaceta no. 105.

Mendoza, Y. \& Mendieta, M. (2006). Ciencias naturales: Segundo año. Managua: MED.

Moreno B., E. \& Cerda H., D. (1998). Formación cívica y social: primer año. Managua: MED.

Rivera A., J.V. (1996). RAAN ratasbaia ritska nani=Los recursos naturales de la RAAN=Natural resources of the RAAN. Alwana, 5, pp. 4-9

Romero V., G. (1998). Formación Cívica y Social: Segundo año. Managua: MED.

Stocks, A. (1994). Estudio socio económico de las comunidades mayangnas, en el territorio indigena de Mayangna Sauni As. Managua: Impresiones Modernas.

Vannini, F. \& Buitrago, J.A. (2002). Ciencias naturales: Segundo año ciclo básico. $3^{\mathrm{a}}$. ed., HISPAMER: Managua.

Williams-G., K., et al. (2006). Abundancia de animales de caza y características de cacería en el territorio indígena de Kipla Sait Tasbaika, reserva de biosfera BOSAWAS. Wani, 46, pp. 37-61.

Cuencas y Sub-cuencas. [mapa]. Recuperado en diciembre del 2011, de hhtp://www.ineter.gob.ni

Los recursos hídricos. (s.f.). Recuperado en diciembre del 2011, de http://www.altervida.org.py/espanol/info_hidricos1.php 